\title{
Vegetation Composition and Ecological Benefits of Home Gardens in the Meegahakiula Region of Sri Lanka
}

\author{
R.L. Senanayake, U.R. Sangakkara ${ }^{1}$, D.K.N.G. Pushpakumara ${ }^{1}$ and P. Stamp ${ }^{2}$ \\ Postgraduate Institute of Agriculture \\ University of Peradeniya \\ Peradeniya, Sri Lanka
}

\begin{abstract}
Clearing of natural ecosystems and land degradation due to unsustainable agricultural practices are becoming threats to the sustainability and productivity of agricultural systems in Sri Lanka. Tropical home gardens can be identified as an alternative, which provide economic and socio-cultural benefits to the subsistence farmers. These home gardens generate income as well as serve as a source of nutrition to the households. Along with the economic value, home gardens are known for their high species diversity. The broad objective of this study was to quantify the species diversity of perennials and annuals by determining the species composition of 30 home gardens in the Meegahakiula region of Sri Lanka. These 30 home gardens were selected randomly from three slope categories according to topographical arrangement as steep (> 30\% slope), moderate (10-30\% slope) and flat land $(<10 \%$ slope). The Shannon Weiner and Margalef indices were calculated in order to ascertain the levels of diversity of perennial and annual species in these home gardens. The relative importance value was calculated separately for perennial species and annual species. The Shannon Weiner index of perennial species was similar to that of the natural forest in Kerala, India and home gardens in Indonesia. Five major perennial species categories and six important annual species were identified in home gardens. There was a greater distribution of annuals in home gardens in the flat land category while the home gardens with moderate and steep land category had a distribution of perennial species.
\end{abstract}

\section{INTRODUCTION}

Clearing of primary forests to develop agricultural systems has increased during the past few decades in many tropical countries, including Sri Lanka. Due to the scarcity of land, people tend to clear the forests and establish crops. Crops, land and management practices will become a problem in the near future as it affects the balance of environmental processes. Therefore, sustainable agricultural systems should be promoted. Tropical home gardens supply all or most of the basic material requirements for a family from a small area of highly diverse tree, palm and vine crops and from short term ground level crops grown beneath these tree crop canopies (McConnell, 1992). The features of home gardens are year round production of food and a wide range of other products such as firewood, fodder, spices, medicinal plants and ornamentals, decreased risks of production failure due to high diversity of species, increased resource productivity over time, expansion of the amount and quality of labor applied in the farm, provision of output flexibility and alternative production if

1 Department of Crop Science, Faculty of Agriculture, University of Peradeniya, Sri Lanka

2

Swiss Federal Institute of Technology (ETH), Zurich, Switzerland 
unfavorable circumstances develop, potential to serve as repositories of genetic diversity, and acting as insurance against pests and disease outbreaks (Cromwell et al., 1999).

Home gardens in Sri Lanka are also considered as sustainable systems of agroforestry. However, home gardens in the intermediate zone of Sri Lanka have not been evaluated in depth for their species composition. Thus, the broad objective of this study was to quantify the species diversity of perennials and annuals by determining the species composition of 30 home gardens in the Meegahakiula region of Sri Lanka and to examine the agronomic characteristics of selected home gardens in the different land categories with their economic contribution to the respective households over a period of one year.

\section{MATERALS AND METHODS}

\section{Study area}

The project was located in the Walapane valley, which belongs to the Meegahakiula region. Meegahakiula is situated between Mahiyanganaya and Badulla, and lies in the north-eastern extremities of IM1c. The area was divided into three groups according to the topographic arrangement as steep ( $>30 \%$ slope $)$, moderate $(10-30 \%$ slope $)$ and flat land $(<10 \%$ slope). The period of study was from October 2007 to September 2008, to include the Maha (major cultivating season; September 2007 - February 2008) and Yala (minor cultivating season; March 2008 - August 2008) seasons and the two intermediate seasons.

\section{Data collection}

In order to have an unbiased representation from each topographic category, ten home gardens were selected by simple random sampling method. Thus, in total, thirty (30) home gardens were evaluated, which was $40 \%$ of the total home gardens in the Meegahakiula area. For each home garden, a complete inventory was carried out to assess the total species diversity and abundance of crops. The occurrence of weeds and ornamentals were documented, but not quantified. Based on the information and literature, crop species were classified into different categories such as spices, fruits, vegetables, fuel-wood plants, medicinal plants, and multipurpose trees.

A survey questionnaire was used to collect information, which was distributed to farmers every month, to be filled by the respective farmers. The data of crop yields were obtained by survey questionnaire and interviewing the households of home gardens and the amounts used for home consumption and marketed were recorded. At the end of each season, the total yield, quantity sold and used for home consumption were calculated based on the information obtained through the survey.

\section{Data analysis}

Agro-ecological importance values were calculated on the basis of three criteria: the frequency of a species occurring across the entire site, the density of individuals of a species and the area occupied by a species (dominance) (Mohan et al., 2007).

The diversity, richness and evenness of species were computed using the Shannon Weiner and Margalef Indices (Mohan et al., 2007), which were non-parametric variables. The 
Freidman's test was used for analysis of data without replicates (StatSoft, Inc., 2007). The estimated productivity of home garden species was based on the surveys and established information about productivity and crop yields. The productivity of minor crops, such as vegetables for household consumption, was estimated based on the farmers' responses with regard to intensity and frequency of use.

Analysis of variance (ANOVA) was conducted, and the LSD $(p=0.05)$ test were used to determine any significant differences among the treatment means. The data were subjected to the General Linear Model (GLM), and Statistical Analysis Software (SAS) was used to analyze the data (SAS, 1999).

\section{RESULTS AND DISCUSSION}

\section{Structure of home gardens}

The size of the home gardens averaged 0.3 ha, but the home gardens in the moderate land category were smaller than those in the flat and steep land category (Table 1). The oldest home gardens were found in the moderate land category where the extents of landholdings were smaller due to their subdivision from generation to generation when land is endowed from parents to children. Sunwar et al., (2006) also reported that land fragmentation is common in Nepal where the parcel size of land decreased during the past 10 to 15 years mainly due to increasing fragmentation of land.

Table 1. Plant diversity parameters for perennial species in home gardens in three slope categories in the Meegahakiula region

\begin{tabular}{lrrr}
\hline Structural attributes & \multicolumn{1}{c}{ Flat } & \multicolumn{1}{c}{ Moderate } & \multicolumn{1}{c}{ Steep } \\
\hline Area (ha) & $0.30^{\mathrm{a}} \pm 0.51$ & $0.18^{\mathrm{b}} \pm 0.22$ & $0.30^{\mathrm{a}} \pm 0.91$ \\
Age (years) & $16.00^{\mathrm{b}} \pm 2.66$ & $22.00^{\mathrm{a}} \pm 3.12$ & $13.00^{\mathrm{b}} \pm 2.34$ \\
Mean number of species & $43.00^{\mathrm{a}} \pm 5.54$ & $37.00^{\mathrm{a}} \pm 8.16$ & $41.00^{\mathrm{a}} \pm 3.33$ \\
Mean Shannon Index $\mathrm{H}^{1}$ & $1.55^{\mathrm{a}} \pm 0.32$ & $1.52^{\mathrm{a}} \pm 0.34$ & $1.77^{\mathrm{a}} \pm 0.34$ \\
Mean Margalef Index & $2.87^{\mathrm{a}} \pm 0.93$ & $2.68^{\mathrm{a}} \pm 0.47$ & $2.78^{\mathrm{a}} \pm 0.57$
\end{tabular}

Means in a row with different letters are significantly different at $\mathrm{p}=0.05$.

The mean number of species, Shannon Weiner and Margalef Indices for perennial species in home gardens in three slope categories are shown in Table 1. Perennial species were identified in the three slope categories with the exception of weed and ornamental species. The highest Shannon Weiner Index (1.77) was found in the steep land category due to a more uniform distribution of perennial species, such as Ficus racemosa (Attekka), Syzygium spp (Damba) and Thespesia populnea (Gansuriya), which were rare in the flat and moderate land categories. A research study conducted in the home gardens in Kerala, India yielded Shannon Indices comparable to this study, ranging from 1.12 to 3.0 (Kumar et al., 1994), which recorded values similar to that of a government-owned forest in India. The Shannon Index values reported by Gajesani and Gajesani (1999) for home gardens in Thailand, which were comparable to the results of the present study, were also fairly close to the species diversity indices for a dipterocarp forest ecosystem in northeastern Thailand.

In the present study, the lower Shannon Index value reported in the flat land category could also be due to uneven distribution of perennials where species such as Musa sp, Gliricidia 
sepium and Tectona grandis, were abundant while Flacourtia ramontchi, Cassia fistula and Ceiba pentendra were found in lesser numbers. The species richness of perennials as indicated by the Margalef Index (Table 1) was greater in the home gardens in the flat land category (2.87) as there were more species than in the home gardens in moderate and steep slope land categories. The fact that there was no greater difference in Margalef Indices for perennials in the home gardens across land categories of home gardens implies that species richness is not affected by the size of the home garden (Varghese and Balasubramanyan, 1998).

Five major perennial plant categories were ecologically important in the gardens (Fig. 1). The fuel-wood (G. sepium) and fruit species were important in all the home gardens, while the timber trees were relatively more important for those in the moderate land category than in the flat and steep land categories. In the flat land category, the importance of timber species was lower when compared to those in the moderate and steep land categories, as the presence of more timber species can become a problem for vegetable production in the former. In the steep land category, the relative importance value of the spice crops was low as the lands are highly eroded and the contents of $\mathrm{N}(0.95 \mathrm{Mg} \mathrm{N} \mathrm{g-1} \mathrm{soil)} \mathrm{and} \mathrm{organic} \mathrm{matter}$ $(1.07 \%)$ were lower when compared to the home gardens in the other two land categories.

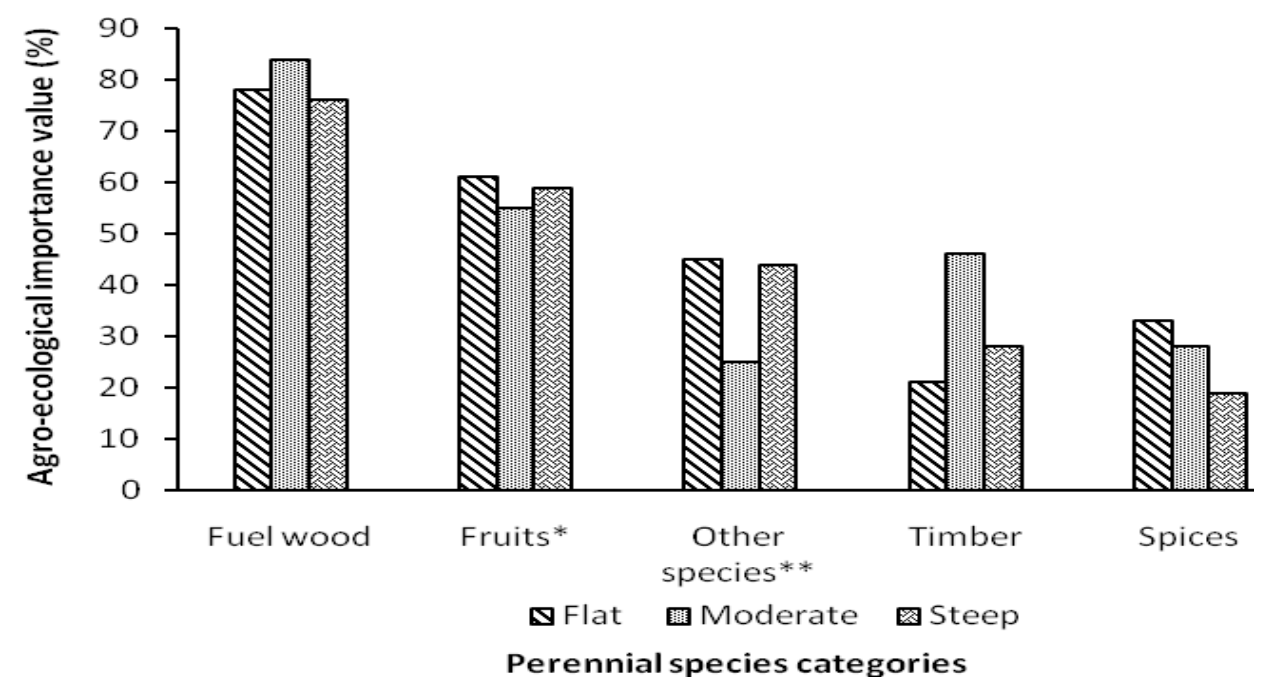

Fig. 1. Relative importance values of perennial species in the home gardens at Meegahakiula, based on frequency, density and dominance

Fuel-wood: Gliricidia sepium, Albizia lebbeck

*Fruits: Carica papaya (Papaya), Musa spp. (Banana), Mangifera indica (Mango), Ananas comosus (Pineapple), Citrus spp., Annona reticulata (Anona), Punica granatum (Pomegranate), Psidium guajava (Guava), Elaeocarpus serratus (Weralu), Muntingia calabura (Jam), Passiflora edulis (Passion fruit), Syzygium jambos (Jambu), Limonia acidissima (Wood apple), Flacourtia indica (Ugurassa)

**Other species: Anacardium occidentale (Cashew), Artocarpus heterophyllus (Jak fruit), Cocos nucifera (Coconut), Areca catechu (Arecanut), Caryota urens (Kithul), Tamarindus indica (Tamarind)

Timber: Tectona grandis, Berreya cordifolia, Thepesia populnea, Chloroxylon swietenia, Grewia spp., Eucalyptus alba

Spices: Piper nigrum, Zingiber officinale, Curcuma domestica, Cinnamomum verum 


\section{Diversity of annual species}

The species diversity of vegetables was not significantly different among the home gardens in the three land slope categories. Depending on the season, availability of resources and the preference of the farmer, the vegetable species cultivated in the home gardens varied. The tuber crop Dioscorea alata was abundant in home gardens in the moderate land category, and Manihot esculenta in home gardens in the steep slopes. The farmers in the moderate land category cultivated $D$. alata as the ground in the home garden is shaded by perennial species. Under shaded conditions, D. alata grows well even during periods of mild drought (May to June). Farmers in home gardens in the steep slopes cultivated M. esculenta as it grows well on highly eroded soils. The farmers' perception, too, was that M. esculenta can grow well on highly eroded soils and that it tolerates drought better than D. alata.

\section{Variation in the diversity indices for annual crops in different cropping seasons}

The mean Shannon Index was higher in home gardens in the flat category in all four cropping seasons (Table 2). This was probably due to the greater productivity of the soil and the availability of resources in the flat land category when compared to the moderate and steep slope categories.

Table 2. Variation in the Shannon Index in different cropping seasons

\begin{tabular}{lcccc}
\hline & Flat & Moderate & Steep & $\mathrm{P}^{* *}$ \\
\hline Maha season & $1.97^{\mathrm{ax}}$ & $1.29^{\mathrm{bxy}}$ & $0.98^{\mathrm{bx}}$ & $<0.0001$ \\
Intermediate 1 & $1.32^{\mathrm{ay}}$ & $1.09^{\mathrm{axy}}$ & $1.02^{\mathrm{ax}}$ & 0.6991 \\
Yala season & $1.65^{\mathrm{ax}}$ & $1.42^{\mathrm{bx}}$ & $1.30^{\mathrm{cx}}$ & 0.0993 \\
Intermediate 2 & $1.20^{\mathrm{ay}}$ & $0.88^{\mathrm{ay}}$ & $1.16^{\mathrm{ax}}$ & 0.6386 \\
\hline $\mathrm{P}^{*}$ & 0.0002 & 0.0271 & 0.2581 &
\end{tabular}

Means with the same letters are not significantly different according to the LSD test $(\mathrm{p}=0.05)$.

$\mathrm{a}, \mathrm{b}, \mathrm{c}$ indicate the differences among flat, moderate and steep slope categories.

$\mathrm{x}, \mathrm{y}$ indicate the differences among seasons (Maha, intermediate1, Yala, intermediate2).

$\mathrm{P} * *$ indicates the probability values for the three slope categories.

$\mathrm{P} *$ indicates the probability values for the different seasons.

The home gardens in the flat land category were intensively managed for commercial vegetable production. When comparing the four seasons, a higher Shannon Index ( $\mathrm{p}=$ 0.0002) was found in the Maha and Yala seasons. The northeast monsoon brings the most rainfall (Maha season) to this area with less but still considerable rainfall in the Yala season. There is less rainfall during the two intermediate seasons. However, in 2008 there were some unexpected changes in the pattern of rainfall which may cause the variations in Shannon Index for annuals in the home gardens. There was unexpected rainfall in the intermediate season 1, which affected the growth of annual crops. This had a positive effect, as the farmers planted crops earlier in home gardens and thus, the harvest in the Yala season was higher. A study conducted in Kerala, India found Shannon Indices similar to those observed in this study, ranging from 0.79 to 1.32 (Peyre et al., 2006).

A widespread constraint to crop growth is the poor availability of soil nutrients, largely due to the low inherent fertility of highly weathered soils (Sanchez et al., 1996). This problem is further aggravated in home gardens in the steep slope categories as a result of severe soil erosion and inadequate land management. 
Species richness (Margalef Index) of the annuals in home gardens varied depending on the season as well as the requirements of the households (Table 3). In the flat land category, species richness was lower during the Maha and intermediate seasons when compared to the steep slope category as the production in the flat land category was mainly based on commercial aspects (Fig. 2). The home gardens in the moderate and steep land categories were mainly for producing annual crops for the household. In this category, the number of species was higher and the number of individuals in each species was lower. Peroni and Hanazaki (2002) explained that the inter-household differences in species richness are influenced by garden size, land assets, age of garden and gender of labour provided by the members of the household, all of which were confined in this study.

Table 3. Variation in the Margalef Index in four cropping seasons

\begin{tabular}{lcccc}
\hline & Flat & Moderate & Steep & $\mathrm{P}^{* *}$ \\
\hline Maha season & $1.31^{\mathrm{ax}}$ & $0.67^{\mathrm{bxy}}$ & $1.42^{\mathrm{ax}}$ & 0.0110 \\
Intermediate 1 & $0.92^{\mathrm{ayz}}$ & $0.50^{\mathrm{ay}}$ & $0.90^{\mathrm{ax}}$ & 0.4656 \\
Yala season & $1.15^{\mathrm{axy}}$ & $0.91^{\mathrm{bx}}$ & $1.07^{\mathrm{ax}}$ & 0.2038 \\
Intermediate 2 & $0.72^{\mathrm{bz}}$ & $0.49^{\text {by }}$ & $1.15^{\mathrm{ax}}$ & 0.0045 \\
\hline $\mathrm{P}^{*}$ & 0.0033 & 0.0299 & 0.3511 & \\
\hline
\end{tabular}

Means with the same letters are not significantly different according to the LSD test $(\mathrm{p}=<0.05)$.

$\mathrm{a}, \mathrm{b}$ indicates the differences among flat, moderate and steep slope categories.

$x, y, z$ indicates the differences among seasons (Maha, intermediate1, Yala, intermediate2).

$\mathrm{P} * *$ indicates the probability values for the three slope categories.

$\mathrm{P*}$ indicates the probability values for different seasons.

The study revealed that fifteen major important annual crops were prevalent and ecologically important in the home gardens evaluated. For convenience, only six major annual crops found in the home gardens in all three slope categories were discussed (Fig. 2). Winged bean was overwhelmingly important in the home gardens in flat land, while tuber crops were relatively more important in those in the moderate and steep land categories.

The home gardens in the flat land category had a greater number of species (Fig. 2) with higher relative importance values, due to market-oriented production. Farmers sold the products of their home gardens namely, winged bean (Rs. 22-24/kg), tomato (Rs. 50-52/kg), and brinjal (Rs. 12-15/kg) at the Meegahakiula or Badulla Markets. In the moderate and steep land categories the production of vegetables was, mostly for own consumption, except chilli (Rs. 50-55/kg) and brinjal in moderate, and brinjal and tomato in steep land categories, where the excess was sold. More than $75 \%$ of the tuber crops of home gardens in all land categories were sold at Rs. $18-25 / \mathrm{kg}$ due to lower household consumption. In the flat land category, winged bean could be considered as the most important crop due to the higher relative density and relative dominance of the crop when compared to other vegetable species. In the moderate and steep categories tuber crops (cassava and yams) could be considered important as farmers had already established tuber crops in their home gardens before the commencement of the major season. 


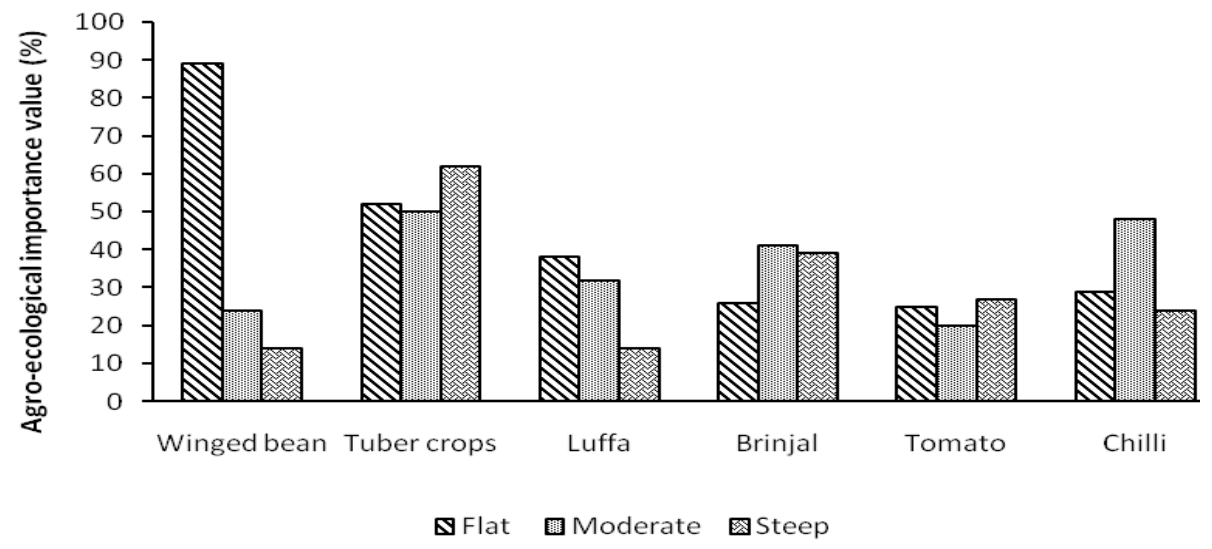

Annual crop species

Fig. 2. Relative importance values of annual crop species in the home gardens at Meegahakiula, based on frequency, density and dominance

\section{Monthly consumption of vegetables from home gardens}

With the implementation of the Sustainable Agricultural Development Project (SADP) in the Meegahakiula region by Ceylon Tobacco Company, the dependency on vegetable purchases declined over the past few years (Fig. 3). The peak production of vegetables in home gardens was in March and April followed by May and June. After June, with the onset of drought, the yields have decreased. Although some crops produced sufficient yield for household consumption, the yields were low and unpredictable during the Yala season.

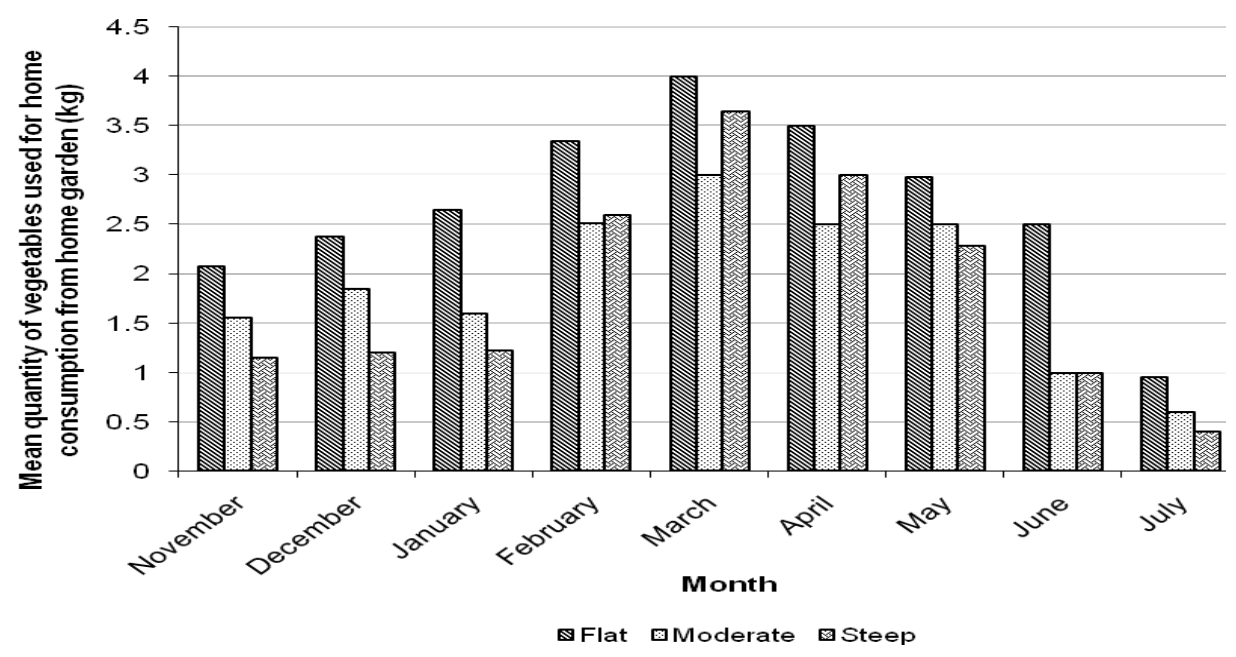

Fig. 3. Mean monthly consumption of vegetables from home gardens in the three slope categories 
Households in the flat land category consumed most of the vegetables produced in their own gardens (Fig. 3) as a result of intensive vegetable production. Therefore, they depended less on vegetables purchased from the markets than the households in the moderate and steep land categories. More vegetables were produced in the flat land category than in the other two categories (Fig. 2). Households in the steep slopes consumed more produce from their home gardens in March and April than the other two categories, and hence fewer vegetables were purchased from the market during this period.

The mean amount of vegetables produced in home gardens for consumption and the monthly expenses for purchased vegetables of the households in all three land slope categories had a negative correlation. The impact was greater in the flat land category because the home gardens produced more vegetables, except for during severe periods of drought. The expenditures for purchasing vegetables were highest in the home gardens from the steep slope land category. Households in this category spent Rs. 22,899 over the period of study (12 months) for purchasing vegetables, while households in the steep slope spent Rs. 24,256.

The production patterns observed in this study also imply that the nutritional status of households was best in the flat land category where more vegetables were produced. In contrast, when vegetables had to be purchased, the purchases are limited to reduce expenditures thus reducing the nutritional status of the household diet. However, this aspect should be studied further.

\section{CONCLUSIONS}

The results of the present study revealed that the species diversity of perennial plants was greater in the home gardens in the steep slopes, while species diversity of annuals were greater in the home gardens in the flat land category. The home gardens are important for providing both economic and ecological benefits, and they are also important socially and culturally, both for the farmer and the community. In the current context, the Meegahakiula farmers not only meet their subsistence requirements from the respective home gardens, but also make use of the home garden as a source of income by marketing the produce of commercial crops. However, it is important to educate them on the adequate nutrition and food supply.

The ecological benefits such as land protection from erosion is minimized in the home gardens in the steep slope categories when compared to those in moderate and flat lands. For the hilly slope lands, a more diverse mixed cropping system with a combination of perennial and annual species would be more suitable than establishing cropping systems giving more prominence to annuals.

\section{ACKNOWLEDGEMENT}

The fieldwork for this research was accommodated at the Faculty of Agriculture, University of Peradeniya, Sri Lanka, through the financial support provided by the North South Centre, Switzerland. The authors thank the farmers in the Meegahakiula area who participated in the survey and for their support extended to complete this study. 


\section{REFERENCES}

Cromwell, E., Cooper, D., and Mulvany, P. (1999). Agriculture, biodiversity and livelihoods: Issues and entry points for development agencies. Overseas Development Institute, London. http://nt1.ids.ac.uk/eldis/agbio.htm

Gajaseni, N., and Gajaseni, J. (1999). Ecological rationalities of the traditional home-garden system in the Chao Phraya Basin, Thailand. Agroforestry Systems 46: 3-23.

Kumar, B.M., George, S.J., and Chinnamani, S. (1994). Diversity, structure and standing stock of wood in the homegardens of Kerala in peninsular India. Agroforestry Systems 25: 243-262.

McConnell D.J, (1992). The forest garden farms of Kandy, Sri Lanka. FAO, Rome.

Mohan, S., Ramachandran, P. K., Nair, P. K., and Alan, J. Long. (2007). An assessment of ecological diversity in home gardens: A case study from Kerala State, India. J. Sust. Agric. 29(4): 135-153.

Peroni, N., and Hanazaki. (2002). Current and lost biodiversity of cultivated varieties, especially cassava, under Swidden cultivation systems in Brazilian Atlantic forest agriculture, Ecosystems and environment 92: 171-183.

Peyre, A., Guidal, A., Wiersum, K. F., and Bongers, F. (2006). Dynamics of homegarden structure and function in Kerala, India. Agroforestry Systems 66: 101-115.

Sanchez, P.A., Shepherd, K., Meredith, J., Soule, F.M., Buresh, R.J., Izac, A.N., Uzookuwunye, A., Kwesiga, F.R., Ndiritu, C.G. and Woomer, P.L., (1996). Soil fertility replenishment in Africa: an investment in natural resource capital. In: Buresh, J., Sancehz, P.A., Calhoun, F.G. (Eds.), Replenishing Soil Fertility in Africa. 1-46. Soil Science Society of America Special Publication No. 51. SSSA, Madison, WI.

SAS (1999) SAS User's Guide: Basics. SAS Institute Inc, Cary, NC, USA

StatSoft, Inc. (2007). Electronic Statistics Textbook. Tulsa, Retrieved October 29, 2008, from: http://www.statsoft.com/textbook/stathome.html

Sunwar, S., Thornstrom, C. G., Subedi, A., and Bystrom, M. (2006). Home gardens in western Nepal: Opportunities and challenges for on-farm management of agrobiodiversity. Biodiversity and Conservation, Issue 15: 4211-4238.

Varghese, A.O., and Balasubramanyam, K. (1998). Structure, composition and diversity of the tropical wet evergreen forest of the Agasthyamalai region of Kerala, Western Ghats. Journal of South Asian Natural History 4: 87-98. 